\title{
As reduções e as línguas: apontamentos sobre a formação do guarani paraguaio
}

\section{Joyce Palha Colaça ${ }^{1}$}

Resumo: O presente texto se dedica a discutir questões em torno do processo de gramatização da língua guarani no Paraguai, tomando como ponto de partida (não no sentido de originário) o período colonial, para, então, propor uma leitura sobre o status da língua guarani em situação de plurilinguismo naquele momento histórico. Para tal, busca-se, a partir dos pressupostos teóricos da Análise de Discurso (MARIANI, 2004, 2007; ORLANDI, 2008 [1990]), em seu entrelaçamento com as discussões propostas por Auroux (2009 [1992]) no campo dos estudos da História das Ideias Linguísticas, mobilizar algumas noções sobre o lugar das línguas indígenas, em especial da língua guarani, e dos indígenas em sua relação com a catequese e com outros agentes deste processo histórico, os freis católicos, a partir do ensino da religião e pela produção de gramáticas das línguas americanas no período colonial. Por esta perspectiva, lançaremos luz sobre as discussões de Melià acerca das gramáticas da língua guarani de Alonso de Aragona e de Antonio Ruiz de Montoya. Com esta análise, buscamos compreender como se deram as condições de gramatização da língua guarani no âmbito das reduções no Paraguai para além das questões formais da língua, focando nosso gesto de interpretação sobre os sentidos produzidos a partir da historicidade deste processo. Palavras-chave: Paraguai. Bilinguismo. Gramatização. Língua guarani.

este artigo, enlaçaremos os sentidos sore a História do Paraguai
aos aspectos que se organizaram em torno da gramatização da língua guarani. Entendemos o período colonial como fundamental para compreender como os habitantes da região que hoje se identifica como o Paraguai (ainda não conformado como uma nação) sofreram os processos históricos que direcionaram a sociedade atual, antes plurilíngue e hoje oficialmente bilíngue. Entendemos que, ao apresentar a complexidade da historicidade do processo de catequese, podemos compreender como se

\footnotetext{
1 Professora Adjunta de Língua Espanhola na Universidade Federal de Sergipe.
} 
organizaram não somente as sociedades daquele momento histórico, mas também os saberes sobre as línguas que naquele espaço circulavam. Assim, para nós, as políticas educacionais/religiosas sobre a população derivam também para políticas sobre as línguas, fazendo significar determinados sentidos e direcionando modos de organização da sociedade. As políticas sobre as línguas indígenas, se analisadas sob o olhar discursivo, nos permitem compreender como os processos de construção de bilinguismos ou de monolinguismos oficiais - como é o caso da maioria das nações americanas na atualidade - são anteriores às ações sobre as próprias línguas, mas se constituem no encontro do imaginário sobre os povos e sua (s) história (s), sobre os sujeitos e seus corpos.

\section{Historicicidade e condições de produção}

O discurso histórico sobre o Paraguai enlaça sentidos para os sujeitos paraguaios desde o período anterior à colonização. Neste artigo que ora se apresenta, trabalharemos com alguns historiadores e estudiosos de outras áreas que versaram sobre as línguas indígenas e sobre o Paraguai (Melià, 2003; Chamorro, 2009; Durán, 2011 [2010]), mas fazendo um deslocamento por entender a história como discurso.

Antes de passarmos a realizar a leitura discursiva dos dizeres da história oficial, valem algumas colocações acerca da organização e das concepções teóricas que aqui se inscrevem. Por uma questão metodológica, não trataremos da situação no continente americano pré-hispânico, por considerar, em nosso estudo, principalmente a relação entre o espanhol e o guarani, cujo encontro se deu após a "descoberta das Américas". Sendo assim, nosso recorte temporal contempla, mais especificamente, os séculos XVII e XVIII, período em que ocorreram as missões jesuíticas no Paraguai. Optamos por utilizar a expressão "descoberta das Américas" entre aspas para fazer referência à vinculação deste sintagma ao discurso da História, 
que vigorou durante quase cinco séculos, sobre a invasão europeia que aconteceu neste continente pelos idos do século XV. Ainda como forma de apresentar nossos primeiros apontamentos, faz-se necessário dizer que, para a Análise do Discurso, os sentidos não têm origem identificada, o que nos conduz a afirmar que os dizeres sobre o Paraguai a partir da colônia possivelmente ressoam sentidos dos períodos históricos anteriores, mas que não é nosso objetivo uma caça a uma origem perdida, principalmente por compreender que não seria possível tal empreitada. É preciso, ainda, por esse motivo, ressaltar que a memória dos dizeres não se organiza cronologicamente, e nossa tentativa de organizar é já um gesto do analista (ORLANDI, 2010 [1994]), baseado nos gestos de pesquisadores que anteriormente trataram dos períodos históricos aqui tomados.

Como ponto inicial, é preciso marcar que a colonização espanhola, no território hoje delimitado como Paraguai, não foi pacífica, como tampouco o foi nos demais espaços latino-americanos. Diferente do que contava o discurso da história, que colocava a descoberta como motivo de alegria para as nações americanas, houve muita resistência por parte dos indígenas aqui estabelecidos frente ao modo de ocupação europeu. De acordo com o discurso da história do Paraguai, houve resistência guarani durante mais de cento e vinte anos, ou seja, a colonização não foi sem embate, sem luta e sem contradições (DURÁN, 2011 [2010], p. 66). Do campo dos estudos da História, de acordo com Durán (ibidem), teria sido fundamental, nesse primeiro encontro, o sistema de reciprocidade familiar, em que espanhóis tomavam como pares mulheres indígenas, conseguindo, assim, além das próprias amantes, alianças familiares, que lhes facilitavam a entrada e a permanência na colônia, em troca de material de ferro e armas de guerra (ibidem). Essas relações entre mulheres indígenas e homens europeus são apontadas como um primeiro momento de encontro linguístico e de sobrevalência/soberania das línguas indígenas no panorama americano, pois, na criação dos filhos, supostamente, a língua guarani prevaleceria no 
Paraguai.

Um fenômeno que marcou a colonização nas diversas partes do continente americano foi a presença dos línguas, intérpretes que aprendiam as línguas indígenas ou indígenas que aprendiam as línguas dos colonizadores, com o objetivo de intermediar as relações entre europeus e indígenas. Mariani (2007), em seu texto Quando as línguas eram corpos, analisa comparativamente os dizeres sobre os línguas na África e no Brasil nos "discursos da colonização", com o objetivo de compreender as representações sobre as línguas e sobre os línguas nos dois espaços. Para a autora,

é possível dizer que, colocadas em circulação a partir dos corpos dos línguas, as línguas constituem não somente um saber lingüístico a ser partilhado, mas também práticas sociais, culturais e religiosas a serem aprendidas ou impostas. Pensemos nos línguas, então, como corpos significantes, corpos atravessados pela linguagem. (MARIANI, 2007, p. 88.)

Tomando as análises de Mariani, podemos afirmar que no corpo dos línguas, "atravessados pela linguagem", se inscrevem "práticas sociais, culturais e religiosas", corpos que significam na história da colonização de modo diferente, a depender, inclusive de sua origem. Como nos ensina a autora, são diferentes os sentidos produzidos para os línguas de origem portuguesa e os línguas de origem americana ou africana. No Paraguai, de acordo com Gómez (2007, p. 78), os primeiros bilíngues espanholguarani teriam sido europeus chegados às terras no início da conquista. Posteriormente, alguns indígenas teriam sido levados à Espanha para aprenderem a língua espanhola e se tornarem «línguas», processo semelhante ao que aconteceu no Brasil, como aponta Mariani:

O termo língua figura principalmente nos textos portugueses a partir do final do século XV, vindo a subs- 
tituir o 'turgimão', que era empregado anteriormente. Segundo os historiadores, esses portugueses que ficavam imersos na cultura local absorvendo ritos e aprendendo a geografia do lugar eram chamados de tangomãos ou lançados. Dito de outro modo, o língua (ou turgimão) designa um lugar de intérprete e uma função: atuar como intermediário em transações comerciais variadas. A atuação dos línguas, portanto, existe antes de a Coroa Portuguesa sedimentar administrativa e religiosamente a terra descoberta, os intérpretes eram deixados na costa para aprender a língua desconhecida, os costumes do lugar, a geografia e a localização das riquezas. ${ }^{2}$ (MARIANI, 2007, p.88-89.)

De acordo com os dizeres da colonização portuguesa, já havia a figura do "turgimão", que tinha como objetivo conhecer a cultura local e aprender a geografia. Como aponta Mariani, o lugar do língua como intérprete estaria marcado por uma função, ou seja, o "língua" era o "intermediário em transações comerciais", deveria conhecer "os costumes do lugar, a geografia e a localização das riquezas". Ainda sobre os línguas, Mariani (2007) afirma que, no discurso colonizador, comparecem de modo diferente os dizeres sobre um ou outro tipo de "língua" de acordo com sua procedência. Os "línguas" indígenas só eram significados como fiéis após se tornarem cristãos.

De outra perspectiva, Gómez (2007), retomando os estudos de Melià, aponta que os motivos pelos quais europeus e indígenas aprendiam a língua do outro já começam a estabelecer as relações dos paraguaios com as línguas até a sociedade atual. Segundo o autor,

Deplorable igualmente fue sobremanera el papel de los intérpretes en la llamada guerra Guaranítica

2 Neste trecho, a autora faz referência ao texto de Boxer (2001), “O império marítimo português” (1415-1825). 
(1750-1756), por las traducciones incorrectas o tendenciosas que daban de los papeles secuestrados a los indios. El padre jesuita añade que este bilingüismo de interpretación ofrece un rasgo característico de lo que será el bilingüismo paraguayo. El guaraní es usado por los castellanohablantes con propósitos típicamente coloniales, sean éstos el ejercicio de un poder político, el intercambio comercial o la misión. Las intenciones de los guaraníes. al hablar español serían diversas: entienden congraciarse con los recién llegados y usar la lengua de quien ya empezaba a llamarse karaí, que se hará sinónimo de 'señor'. (GÓMEZ, 2007, p. 78-79.)

Em termos discursivos, podemos dizer que a memória dos usos do guarani e do espanhol remontam ao período colonial e, embora não seja possível encontrar um início para a memória das relações entre as línguas, podemos dizer que a formação da sociedade colonial que ia se estabelecendo começa a direcionar certos sentidos sobre as línguas, ou como afirma Gómez (ibidem), "este bilingüismo de interpretación ofrece un rasgo característico de lo que será el bilingüismo paraguayo”. Ou seja, retomando Gómez, o uso do guarani pelos europeus teria objetivos colonizadores, enquanto os indígenas buscavam se aproximar dos europeus, a quem já chamavam de senhores. As relações entre as línguas - e os povos - se desenham e se colocam já neste período inicial de colonização.

Ainda pelo discurso da história sobre o Paraguai e suas línguas, uma explicação que ressalta quando se explica a falta de interesse espanhol pela colônia é a falta de metais preciosos naquelas terras. Durán (2011 [2010], p. 64.) afirma que "Después del descubrimiento de la sierra de la Plata (que no era otra cosa que la conquista del Perú), España perdió interés por el Río de la Plata, un territorio que, a pesar del nombre que llevaba, no poseía metales preciosos." (DURÁN, 2011 [2010], p. 64). De acordo com a autora, ainda houve outras incursões para o interior do Paraguai, em regiões mais 
afastadas de Assunção, nessa empreitada exploratória, quando na região de Guairá se teria encontrado algumas "pedras de brilho raro" que teria reacendido o interesse pelo Paraguai:

Pero todo cambió cuando uno de los 'peregrinos' extrajo ante los oidores de Charcas un puñado de piedras de raro brillo provenientes de las minas de Guairá, y aseguró que no eran explotadas por falta de mineros y de un gobernador rico. El menosprecio hacia el Paraguay se transformó, de pronto, en un codiciado interés. (DURÁN, 2011 [2010], p. 65).

Foi então que, em 1575, chegou o novo governador do Paraguai, Ortiz de Zárate, que havia vendido todas as suas possessões no Peru para investir nas promissoras terras mais ao sul do continente. Entretanto, essa confirmação de metais preciosos no Paraguai, segundo os dizeres da história, não coincidia com a realidade. Até os dias atuais, aquela região é conhecida por não ter riquezas minerais. Teria sido também por esta época que chegaram a estas terras os fundadores das reduções guaraníticas na região do Rio da Prata, os franciscanos Luis de Bolaños e Alonso de San Buenaventura. (Ibidem). Estes freis teriam sido, segundo os registros, os primeiros a se preocuparem em aprender o guarani e a fazer-se entender pelos índios, catequizando em língua indígena (MELIÀ, 2003, p. 32).

\section{O Concílio de Lima e a relação entre as línguas na catequese}

Em 1583, o Concílio de Lima havia estabelecido certos moldes para a prática catequética e, em 1603, o Sínodo de Assunção teria retomado estas diretrizes, adaptando-as à realidade paraguaia. De acordo com Melià, dentre as diretivas do Concílio, estava a predicação na "linguagem dos informantes" anterior ao próprio batismo, defendido por Luís de Bolaños e seus companheiros. 
De ahí en adelante la misión se basará en una palabra anunciada en el idioma del indio y que pueda ser comprendida. En el lenguaje de los informantes la predicación es un acto de palabra, tomado en su más amplio sentido, en cuanto esa palabra es el anuncio de verdades cristianas y tiene por fin alcanzar una conversión, que se concretará en el abandono del modo de vida antiguo para dar lugar a la adopción de un modo de ser nuevo basado en la ley cristiana. (MELIÀ, 2003, p. 33)

De acordo com Meliá (ibidem), o ensino da palavra cristã em língua guarani serviria para a aproximação do indígena aos ensinamentos cristãos, sempre com o objetivo de uma posterior adoção ao modo de vida estabelecido pela lei da igreja, baseado nas suas verdades. A predicação aparece como um "ato de palavras" que funcionaria como um "anúncio de verdades cristãs", com o objetivo de "alcançar uma conversão" que culminaria na "adoção do modo de vida baseado na lei cristã". O uso da língua indígena aparece, então, como um instrumento de evangelização e os posteriores avanços com relação ao conhecimento desta língua serão, em geral, com este objetivo. Em Colonização Lingüística, Mariani (2004) aponta este mesmo funcionamento no processo de catequização brasileiro, quando José de Anchieta começou a ensinar as leis cristãs em tupi-guarani. Bolívia, Brasil, México, Paraguai e Peru teriam seguido os desígnios do Terceiro Concílio de Lima (1582-1583) que ordenava que a fé cristã fosse professada nas línguas locais. Teria sido, então, a partir desta decisão que o catecismo passou a ser traduzido e ensinado em guarani, náhuatl, e quéchua $^{3}$.

$\mathrm{Na}$ perspectiva discursiva, podemos considerar que o Concílio

3 "No âmbito da colonização espanhola, as línguas gerais foram objeto de decisão conciliar. Assim, o Terceiro Concílio de Lima (1582-1583) ordena que aos indígenas sejam ensinadas as orações e o catecismo em sua própria língua: o náhuatl no México; o quéchua no Peru; o guarani no Brasil e no Paraguai, até Santa Cruz da Serra."(Tovar/Larrucea de Tovar apud CHAMORRO, 2009, p. 111.) 
de Lima foi, além de um acontecimento histórico, um acontecimento linguístico (GUILHAUMOU, 2009), por fazer inaugurar sentidos sobre as línguas americanas, principalmente com relação ao investimento em novos “objetos linguísticos” (idem). De acordo com Guilhaumou (ibidem, p. 93), que exemplifica especificamente com o caso do francês, o "acontecimento linguístico intervém na hiperlíngua para favorecer a dinâmica inovadora" e acrescenta:

Por esta razão, seu conhecimento é uma abertura para a totalidade de um processo de compreensão que se relaciona ao início de uma reflexão sobre a acontecimentalidade da língua empírica, e, em decorrência, com um desdobramento narrativo da língua francesa constitutiva do imaginário lingüístico que associa a identidade da língua à identidade do nacional. (GUILHAUMOU, 2009, p. 93.)

Segundo o autor, o acontecimento linguístico marca, no caso, o lugar da língua francesa, pela "reflexão sobre a acontecimentalidade da língua empírica", cuja associação se coloca como constitutiva do imaginário da relação existente entre a identidade de uma língua e do nacional. Para o autor (ibidem, p, 131), o acontecimento linguístico inscreve-se em um espaço e tempo determinados e está sujeito à interpretação por sua condição de língua empírica, ou seja, por sua existência em uma língua específica, em espaço e tempo determinados.

O acontecimento discursivo, por sua vez, circularia com mais fluidez por estas barreiras, "num espaço de linhas menos visíveis" (ibidem, p. 131). Conforme Guilhaumou (ibidem, p. 97), “o acontecimento lingüístico situa-se no espaço/tempo fundador de atos de linguagem reguladores do acontecimento discursivo", materializando-se em três formas.

a) sujeitos que dispõem de capacidades lingüísticas próprias, que denominamos de sujeitos cognitivos;

b) objetos lingüísticos, mais particularmente, no con- 
texto da gramatização moderna e contemporânea, instrumentos lingüísticos tais como os dicionários e as gramáticas;

c) uma diversidade de julgamentos desses sujeitos desdobrados nesses instrumentos adequados à tradução abstrata da língua empírica, julgamentos generalizantes sobre os fatos da língua que podem se agrupar sob o rótulo de consciência lingüística (ibidem, p. 97).

Como apresentado pelo autor, o acontecimento linguístico materializa o discursivo pela inscrição na história, em um espaço e tempo determinados, por sujeitos determinados e pela produção de objetos linguísticos próprios. Nas palavras do autor, o acontecimento linguístico recorta o acontecimento. Podemos dizer que o acontecimento linguístico recorta o acontecimento discursivo impondo-lhe limites por sua própria materialização em dada língua. Para nós, interessa por o foco no processo de gramatização das línguas, pela criação de instrumentos linguísticos (AUROUX 2009 [1992]), em determinadas línguas, que se intensifica a partir da determinação do Terceiro Concílio de Lima.

Por essas questões, podemos afirmar que os dizeres do Terceiro Concílio de Lima inauguram sentidos para as línguas indígenas no contexto americano, num espaço e tempo determinados - Bolívia, Brasil, México, Paraguai e Peru, no século XVI - pela sua relação com o ensino cristão e pelo reconhecimento de uma identificação do indígena com suas línguas, funcionando como um acontecimento linguístico. Devemos lembrar que nem os nomes dos referidos países estavam definidos, nem o sentido da “identidade nacional” trazida por Guilhaumou, contudo, a organização espaço-tempo-língua-sujeitos começava a se inscrever discursivamente. Baseados na direção que vai tomar a prática catequética, a partir desta reunião, é que consideramos este Concílio um acontecimento linguístico, na medida em que seus dizeres fundam atos de linguagem (GUILHAUMOU, 2009, p. 97) que irão transformar a relação entre as línguas na colônia. Esse 
acontecimento linguístico fundará, desse modo, discursos sobre as línguas e sobre a catequese, sobre os índios e sua relação com a igreja e sobre os próprios freis franciscanos/padres jesuítas e sua prática religiosa.

Em seu artigo A Língua Brasileira, Orlandi (2002, p. 27) irá dizer que a "colonização produz uma clivagem - disjunção obrigada - que afeta a materialidade da língua brasileira”. Em concordância com as análises da autora, afirmamos que a colonização no Paraguai afeta a materialidade das línguas faladas atualmente, o guarani e o espanhol, que passaram pelo encontro que, embora já ocorresse desde o início da chegada dos espanhóis, se multiplicou quando do Concílio que passava a obrigar aos freis e padres um contato maior com a língua indígena. $\mathrm{O}$ Terceiro Concílio de Lima, tomado aqui como acontecimento linguístico, promove a necessidade de sistematização da língua indígena para a catequese, momento em que a expansão cristã se marca ainda mais fortemente nesse período da colonização linguística (MARIANI, 2004). Ou seja, o processo colonizador europeu nestas terras se fundou e se fortaleceu a partir da ideia de necessidade de civilização dos povos indígenas, que deixou marcas pelo confronto entre línguas diferentes, com memórias diferentes, em um embate marcado historicamente pela desigualdade de forças. Entende-se por colonização linguística este processo desigual, cujas relações de forças favorecem uma língua pela construção de uma memória de legitimação em detrimento da outra. É a língua do colonizador que aparece como língua de civilização frente às línguas indígenas que são significadas como debilitadas, atrasadas, menos complexas. As relações entre os povos se transpõem para as imagens de suas línguas, cuja memória se faz repetir na história, dentre outras formas, pelo funcionamento do acontecimento linguístico permanecendo no "discurso sobre", ao alçar um certo dizer sobre a língua que segue ecoando na memória efeitos de sentido para o guarani, língua e sujeito. A colonização linguística deixa ecos na história paraguaia atual, pelo gesto de catequizar para civilizar que aparecia como 
autêntico naquele período e se mostra eficaz nos dizeres sobre a língua guarani na atualidade, que insiste em significar a língua indígena como atrasada e incapaz de cumprir determinadas funções.

Ainda com relação à colonização linguística no Brasil, Mariani postula que

tematizar a trajetória histórico-linguística constitutiva da institucionalização da língua portuguesa no Brasil é estabelecer uma relação com o projeto colonizador português de civilizar o Novo Mundo. Trata-se de um projeto de colonização lingüística constituído com base no catolicismo jesuítico e em consonância com um imaginário em torno da relação língua-nação vigente do século XVI ao XVIII. Por outro lado, como essa história não se faz sem resistências lingüísticas na colônia, tematizá-la é também discutir o papel da linguagem na transformação de uma colônia em nação independente (2004, p. 21).

Por essa afirmação, podemos retomar o que vínhamos afirmando anteriormente de como o catolicismo começa a construir um lugar para as línguas no novo continente. A autora trata de um "catolicismo jesuítico" em suas análises. Já no Paraguai, a empreitada cristã tem início com dois freis franciscanos, o que nos permite trabalhar com a ideia do catolicismo, mas sem determinar sua filiação, pois, para nós, o processo inicial de catequese se deu de forma bastante parecida, independente de se tratar de jesuítas ou franciscanos. $\mathrm{O}$ modelo europeu posteriormente adotado e promovido nas colônias se reproduzia sob um imaginário já conformado de nação, em torno da relação imaginária entre "língua-nação vigente do século XVI ao XVIII", como aponta Mariani (ibidem).

\section{As reduções e o processo de gramatização da língua guarani}


Um ponto que nos parece fundamental nessa empreitada catequética é que o Concílio teria promovido o início do investimento no processo de gramatização (AUROUX, 2009 [1992]) da língua indígena pela tradução do catecismo. De acordo com Melià (1992), não era difícil demonstrar com provas escritas e testemunhos que a primeira tradução do catecismo era de Luis de Bolaños. Com base em formulações realizadas por Auroux (2009 [1992]), podemos afirmar que esta primeira tradução do catecismo dá início a um processo de produção de conhecimento do sistema linguístico da língua guarani das reduções, bem como do conhecimento metalinguístico sobre a língua guarani. Os freis Luis de Bolaños e Alonso de San Buenaventura, segundo o discurso histórico, já teriam conhecimento da língua oral e iniciaram o processo de escrita da língua indígena ${ }^{4}$. Neste processo, a colonização linguística se marca na própria materialidade da língua, pois sua sistematização segue um modelo europeu, estabelecendo limites e fronteiras na própria escrita, no caso, da língua guarani. A colonização se marca, desse modo, na estrutura da língua, na sua escrita, no seu sistema, no que fica como próprio da língua. É a marca da memória da colonização no sistema das línguas indígenas. A tradição escrita que se impõe sobre uma língua de tradição oral, cuja memória se ressignifica, se recompõe, se reescreve. Para Payer (2005), nessa relação entre a oralidade e a escrita, sempre haverá um impossível de ser formulado, constitutivo na produção discursiva.

um lugar sócio-histórico particular de produção do discurso, que acolhe e possibilita que circulem memórias discursivas que não puderam se inscrever socialmente na ordem da escrita (...) possibilitando dizer algo que ainda não foi dito" ... [Assim,] pelo próprio funcionamento do discurso, não é todo o "não-dito" que pode

4 Ressaltamos que aqui me refiro ao guarani como língua indígena por tratar desta língua no período de colonização. O guarani, na atualidade, não deve ser considerado uma língua indígena, conforme aponta Niro (2010), por se tratar de uma língua falada não somente pelos povos indígenas no Paraguai. 
vir a ser dito: na medida em que sentidos não-ditos adquirem um estatuto da linguagem, haverá sempre algo mais atuando como constitutivo (não-formulável) para o sujeito. Estamos dizendo que, pelo trabalho de formulação do passado, o sujeito pode ter acesso a sentidos que o constituem e que estavam abafados a partir de uma história de silenciamentos (PAYER, 2005: 54).

Há, de acordo com a autora, para o sujeito um "algo mais atuando como constitutivo", da ordem do "não-formulável" nessa escrita de uma língua oral. Dito de outro modo, um impossível de ser dito atua na transposição do oral para o escrito, em que atua também uma memória da oralidade, que não se transpõe como numa possibilidade de escritura mágica de certos sentidos, também determinados pela ordem da oralidade. Indo além, também é necessário considerar que, nesse processo de produção escrita, além da marca da gramática latina na sistematização da língua indígena, é fundamental que apontemos também os temas que se escrevem. A língua indígena passa a ser escrita a partir de uma concepção de língua e a partir de temas do universo cultural cristão europeu. Essa é mais uma marca da colonização como embate, como confronto entre dois imaginários, tal como aponta Mariani (2004). Não só o sistema da língua se organiza a partir de uma escrita latina, como tudo o que é escrito está à revelia do conhecimento indígena sobre sua cosmologia. Impõe-se, num mesmo gesto, tanto a escrita de uma língua que não é a língua guarani, como a escrita de um mundo diferente daquele conhecido e compartilhado pelos indígenas. A cosmologia cristã se impõe sobre a indígena ao ser significada como a real salvação. Entretanto, não há ritual sem falhas, como aponta Pêcheux (2009 [1978]), há sempre o furo no processo histórico, pelo funcionamento de uma resistência que se marca também na língua. Nas palavras de Mariani (2004, p. 21), “como essa história não se faz sem resistências lingüísticas na colônia, tematizá-la é também discutir o papel 
da linguagem na transformação de uma colônia em nação independente." Por essa perspectiva, podemos afirmar que o batismo, que passou a ser realizado nas línguas indígenas, se marca como um gesto de resistência pela língua. A entrada do sujeito na fé cristã se dá, inicialmente, pelo ato do batismo, e ao adotar as línguas indígenas para o que era próprio do imaginário europeu faz ressignifcar o gesto em sua materialidade.

Melià (2003), ao tratar do início da catequese em língua indígena, afirma que os textos foram traduzidos diretamente das cartilhas que eram utilizadas na Espanha naquele período para as diversas línguas do continente americano, numa transposição direta dos ensinamentos cristãos, pela imposição que caracterizou a colonização linguística e a transformação das sociedades indígenas.

La doctrina cristiana es, inicialmente, esa colección de oraciones llamadas comunes que se encontraba, por ejemplo, al final de las cartillas o métodos para aprender a leer, primer librito de texto, muchas veces el único, del que dispondrán los niños escolares en la España de los siglos XVI y XVII. Gran cantidad de esas cartillas eran enviadas a América. Fueron éstas traducidas y adaptadas muy pronto a las lenguas indígenas más diversas; y en lo que hace a la provincia eclesiástica del Perú, se sabe que tales traducciones ya existían antes de 1545 (MELIÀ, 2003, p. 34-35).

A transposição direta das cartilhas impõe aos sujeitos do continente americano sentidos não compartilhados ou, ainda, uma escrita sem sentido, uma imposição de sentidos dominantes que não guardam relação com aquilo que os indígenas conhecem. A imposição da religião atrelada à imposição do sistema escrito promove um impossível de ser dito em língua indígena, uma sistematização do impossível, que se coloca como fundamental pelos colonizadores e que fere a memória discursiva na memória da língua pelo funcionamento da colonização linguística que 
deixa suas marcas.

\section{Sobre duas gramáticas da língua guarani}

É deste período a primeira gramática da língua guarani, do padre Alonso de Aragona, cujos manuscritos foram conservados e publicados recentemente (MELIÀ, 2003, p. 169). De acordo com o autor, esta gramática se apresenta como um método de aprendizagem de guarani para principiantes (MELIÀ, 2003, p. 170), que trata das estruturas básicas da língua guarani através de esquemas gramaticais que retomam categorias gramaticais familiares ao aprendiz europeu.

Así pues, la referencia es la que adopta como base las gramáticas del latín, del griego y del castellano. Pero no se crea con ello que todo lo que no pueda ser encasillado en el esquema preestablecido de las gramáticas latinas o castellanas, deba, por lo mismo, ser eliminado. De hecho, la diferencia que aparece muy pronto entre los modos de decir del guaraní y los del latín o castellano, dará origen a una caracterización propia de la lengua indígena, ya que ésta siempre coincide con el supuesto modelo (MELIÀ, 2003, p. 170).

A primeira gramática da língua guarani é construída a partir do conhecimento linguístico que tem o padre Alonso sobre as gramáticas de língua latina, ou como aponta Auroux (2009 [1992]), o processo de gramatização das línguas americanas se faz a partir do conhecimento das gramáticas do velho mundo. Segundo Melià,

un reproche que se ha hecho con frecuencia a las gramáticas de los misioneros es el de haber sometido el sistema gramatical del guaraní a otro, lejano y extraño, el de la lengua latina, sin que hubiera habido previamente un detenido examen de las característi- 
cas particulares que definían a la lengua guaraní en relación consigo misma. (MELIÀ, 2003, p. 173)

De acordo com o autor, essa apreensão das línguas americanas pelo modelo da língua latina, estranha aos processos de formação das línguas indígenas, foi alvo de diversas críticas, tendo sido uma constante nos dizeres sobre os missioneiros, com relação à gramatização da língua guarani. Contudo, como aponta o autor, mesmo com este modelo latino, a dificuldade em sistematizar a língua guarani apareceu em diversos aspectos do seu sistema linguístico, o que provocou uma série de descobertas por parte dos missioneiros de diferenças fundamentais entre os dois sistemas (MELIÀ, 2003, p. 173).

El Arte de la lengua guaraní, de Antonio Ruiz de Montoya (1724), segue o mesmo modelo latino como a gramática do padre Alonso de Aragona e tem como objetivo oferecer meios para que os missioneiros possam expressar-se e compreender os índios e, embora os dois trabalhos tenham sido forjados paralelamente, Melià (2003, p. 173) afirma que eles não têm uma relação de dependência entre si $^{5}$.

Pelo processo de gramatização da língua guarani das reduções, baseado em modelos das gramáticas de língua latina, Melià (2003) tratará o guarani como "língua reduzida e cristã ${ }^{6}$ ", fazendo uma analogia ao modo como se reduziu a língua indígena a um modelo, na tentativa de compreensão dos fenômenos linguísticos, a partir de esquemas já conhecidos da língua latina, limitando a língua guarani às possibilidades existentes naquela. Uma língua, então, reduzida, e, além disso, cristã, pois apresentava temas basicamente referentes à igreja, por serem os primeiros gramáticos freis e padres que tinham como interesse fundamental o ensinamento da fé cristã.

\footnotetext{
5 Melià (2003, p. 181) cita ainda a gramática do padre jesuíta Francisco Legal, que não chegou a ser publicada. $\mathrm{O}$ autor faz referência a duas obras do autor em sua bibliografia, são elas: LEGAL, F. > a VII: Breve Noticia; LEGAL, F. > a XII: Correciones.

6 “El guaraní, lengua 'reducida’ y cristiana” é um subtítulo da obra de Melià. (2003, p. 179)
} 
Outra questão que aparece fortemente no Paraguai é a formação das reduções como formação social.

Llamamos reducciones a los pueblos de indios que viviendo a su antigua usanza en montes, sierras y valles, en escondidos arroyos, en tres, cuatro o seis casas solas, separados a legua, dos tres, y más unos de otros, los redujo a diligencia de los padres a poblaciones grandes, y a vida política y humana, a beneficiar algodón con que se vistan. (MONTOYA apud MELIÀ, 2003, p.157) 7

Este gesto que reduziu os indígenas a "povoados grandes, e a vida política e humana" foi uma imposição do modo de organização da vida em comunidade, desrespeitando o funcionamento da estrutura da sociedade indígena paraguaia. De acordo com a análise de Melià,

el proyecto de la reducción es a la vez una empresa religiosa y una realización sociocultural, que afectaba de entrada la estructura misma de la nación guaraní. La reducción significa el paso de una vida un tanto dispersa en pequeños grupos, como era practicada por los guaraníes, a una vida estable y organizada en concentraciones mayores (2003, p. 157).

O sistema colonizador europeu se instalou no continente americano, trazendo, então, uma língua, uma religião e um modo de organização social distintos dos que aqui já existiam. Uma imposição completa que nega qualquer possibilidade de manutenção do sistema indígena vigente, substituindo suas formas sagradas, sua ordem comunitária, suas línguas. Silencia-se, num gesto simbólico, pela língua, todo o conhecimento do mundo indígena acerca do mundo e das relações interpessoais anteriores

7 A obra citada por Melià, neste trecho: MONTOYA, Conquista, 1989, p. 58. 
à chegada do colonizador. Marcam este período uma violência física e simbólica no corpo do índio, pela negação de sua língua, de sua fé e de sua sociabilidade. A tensão, no entanto, sempre existe. As fronteiras do ideológico se marcam e se mostram frágeis nos gestos simbólicos da própria religião, como apontamos anteriormente. O batismo, sacramento que marca o início da vida religiosa na fé cristã, é realizado em língua guarani. Abre-se espaço para o furo no modo como a catequese se constrói atrelada a um novo modo de significar, na língua do outro. É desta tensão que se trata a colonização histórica e linguística, em que não existe uma imposição sem resistência, sem um encontro das diferenças que se colocam tanto na língua como no modo como ocupam o espaço os povos americanos e os europeus. Esse encontro, marcado e significado pela língua, afeta os dois imaginários de maneira desigual na relação de forças, por aqueles que detêm o poder da escrita aliado ao poder bélico. No jogo de forças que se colocava nesta tensão entre os dois imaginários, em que ficaram os textos dos europeus que diziam sobre os índios (ORLANDI, 2008 [1990]), os europeus eram significados/se significavam como superiores enquanto os indígenas eram significados pela diferença, a partir de espectros de uma sociedade diferente da sua.

\section{Língua reduzida e gramatizada: a base do guarani para o} bilinguismo oficial da atualidade

Apesar de todas as questões apontadas como marcas no simbólico de uma colonização opressora, a gramatização da língua guarani, mesmo que a partir do modelo latino, produziu um espaço em que a língua guarani foi o modo de comunicação mais eficaz nestas colônias, pela construção política de um lugar que servia ao conquistador. Essa tentativa de apreensão e de aprendizagem do guarani promoveu a língua guarani como língua geral do Paraguai, submetendo a elas outras línguas indígenas 
aí existentes, incluindo a própria língua espanhola. Pela sistematização da língua indígena das reduções a partir do Concílio de Lima e do Sínodo de Assunção, bem como pelo aparecimento dos primeiros instrumentos linguísticos (AUROUX, 2009 [1992]) em língua guarani - a "Gramática de Alonso de Aragona" e "El arte de la lengua guaraní, de Antonio Ruiz de Montoya" - possibilitaram que a língua guarani fosse ocupando determinados espaços na comunidade naquele momento histórico. Como o processo de gramatização das línguas não está separado da historicidade dos processos que o produziram, lembramos que também foi fundamental para a permanência do guarani o fato de haver um pequeno número de hispano-falantes letrados na colônia, bem como ressaltar acerca dos discursos sobre a falta de interesse econômico na história da região, tema sobre o qual nos debruçamos no início deste artigo.

O guarani jesuítico (MELIÀ, 2003), este guarani gramatizado para o ensino da catequese, já não era mais o guarani dos indígenas que o falavam como língua materna, era já outro sistema linguístico. $O$ estudo e a apropriação da língua guarani pelos franciscanos e jesuítas, a partir dos modelos das línguas latinas, sistematizou as línguas indígenas do continente americano a partir do seu conhecimento de funcionamentos linguísticos diferentes, tanto no que diz respeito à sintaxe, quanto à fonética e morfologia das palavras, como pela própria representação do que deveria ser escrito/produzido como resultado do processo catequético.

Com base nas noções de língua fluida e língua imaginária (ORLANDI e SOUZA, 1988), podemos afirmar que o gesto de escrita da língua já faz apreender uma outra língua, uma sistematização de língua não-fluida, uma língua que é encaixotada à força para ser ensinada. $\mathrm{O}$ guarani jesuítico foi, deste modo, uma tentativa de apreensão da língua a partir de um modelo anterior, que já era uma tentativa de apreensão das línguas do velho mundo. Uma caixa dentro de outra caixa, um sistema formatado a partir de outro sistema, também inventado das línguas latinas. 
O guarani jesuítico foi, então, uma língua imaginária sistematizada a partir de um imaginário de língua.

\section{Referências}

ALFARO, Consuelo Lagorio. Norma e bilinguismo no espanhol americano: o caso andino. In: BAGNO, Marcos. LAGARES, Xoán (Orgs.). Políticas da norma e conflitos linguísticos. São Paulo: Parábola Editorial, 2011, p. 193214.

AUROUX, Sylvain. Filosofia da linguagem. São Paulo, SP: Parábola Editorial, IPOL, 2009.

A revolução tecnológica da gramatização. $2^{\mathrm{a} e d .}$ Campinas, SP: Editora da Unicamp, 2009 [1992]). 144p.

CHAMORRO, Graciela. Sentidos da conversão de indígenas nas terras baixas sul-americanas: uma aproximação linguística. In: SUESS, Paulo. MELIÀ, Bartomeu. BEOZZO, José Oscar. PREZIA, Benedito. CHAMORRO, Graciela; LANGER, Protásio. Conversão dos cativos: povos indígenas e missão jesuítica. São Bernardo do Campo, SP: Nhanduti Editora, 2009, p. 111-128.

DURÁN, Margarita Estragó. Conquista y colonización (1537-1680). In: TELESCA, Ignacio. (org.) Historia del Paraguay. $3^{\text {a }}$ ed. Paraguai: Taurus. (Grupo Santillana): 2011 [2010]. p. 63-86.

GUILHAUMOU, Jacques. Linguística e história. Percursos analíticos de acontecimentos discursivos. São Carlos: Pedro \& João Editores, 2009.

MARIANI, Bethania. Colonização linguística: línguas, política e religião no Brasil (séculos XVI a XVIII) e nos Estados Unidos da América 
(século XVIII). Campinas: Pontes, 2004.

A língua como questão nos primórdios da história da colonização africana: a Crônica da Guiné, de G. E. de Zurara. In: Gragoatá, 19, Niterói: PG Letras, 2005.

- Quando as línguas eram corpos: sobre a colonização lingüística portuguesa na África e no Brasil. In: Orlandi (org.). Política Linguística no Brasil. Campinas, SP: Pontes Editores, 2007, p.83-112.

MELIÀ, Bartomeu. La lengua guaraní en el Paraguay colonial. Assunção, Paraguai: Centro de Estudios Paraguayos Antonio Guasch, 2003. 400p.

. Bilingüismo y tercera lengua en el Paraguay. Asunción: Universidad Nuestra Señora de la Asunción, 1975.

NIRO, Mateo. El guaraní como lengua oficial: entre el nacionalismo y la integración regional. In: CELADA, María Teresa. FANJUL, Adrián Pablo. NOTHSTEIN, Susana. Lenguas en un espacio de integración: acontecimientos, acciones, representaciones. Buenos Aires: Editorial Biblos, 2010. p. 209-235.

ORLANDI, Eni. SOUZA, Tânia C. C. Língua fluida e língua imaginária.

ORLANDI, Eni. (Org.) Política linguística na América Latina. Campinas, SP: Pontes Editores, 1988.

ORLANDI, Eni. Língua e conhecimento lingüístico: para uma História das Idéias no Brasil. São Paulo: Cortez Editora, 2002a. 320 p.

. Terra à vista. Discurso do confronto: velho e novo mundo. 2 ed. Campinas, SP: Editora da Unicamp, 2008 [1990]). 288 p.

(Org.). Gestos de leitura: da história no discurso. Campinas, SP: Editora da Unicamp, 2010. 276p. 


\section{PÊCHEUX, M. Só há causa daquilo que falha ou o inverno político francês:} início de uma retificação. In:___. Semântica e discurso. Trad. Eni

Orlandi et al. 4. ed. Campinas, SP: Editora da Unicamp, 2009 [1978], p. 269-281.

Reductions and languages: notes on the formation of paraguayan guarani

Abstract: This text is dedicated to discussing issues surrounding the process of grammarization of the Guarani language in Paraguay, taking as a starting point (not in the original sense) the colonial period, and then proposing a reading on the status of the Guarani language in situation of plurilingualism at that historic moment. To this end, we seek, from the theoretical assumptions of Discourse Analysis (MARIANI, 2004, 2007; ORLANDI, 2008 [1990]), in their intertwining with the discussions proposed by Auroux (2009 [1992]) in the field of studies of the History of Linguistic Ideas, to mobilize some notions about the place of indigenous languages, especially the Guarani language, and of indigenous people in their relationship with catechesis and with other agents of this historical process, the Catholic friars, from the teaching of religion and the production of grammars of American languages in the colonial period. From this perspective, we will shed light on Meliàs discussions on the Guarani language grammars of Alonso de Aragona and Antonio Ruiz de Montoya. With this analysis, we seek to understand how the conditions of grammarization of the Guarani language took place within the scope of the reductions in Paraguay beyond the formal issues of the language, focusing our gesture of interpretation on the meanings produced from the historicity of this process.

Keywords: Paraguay. Bilingualism. Grammatization. Guarani language.

Recebido em: 01/12/2020

Aceito em: 07/06/2021 